\title{
Threatened Aortic Injury by Thoracic Pedicle Screw: A Case Report
}

\author{
Amadou Ndiassé Kassé1 ${ }^{*}$, Souleymane Diao1, Magatte Gaye², Jean Claude Sané1, \\ Jean Marie Vianey Hope', Karim Hemmam¹, Babacar Thiam', Pape Adama Dieng3, \\ Mouhamadou Habib Sy ${ }^{1}$ \\ ${ }^{1}$ Orthopedics and Trauma Surgery Department of Grand-Yoff General Hospital, Dakar, Sénégal \\ ${ }^{2}$ Neurosurgery Department of Grand-Yoff General Hospital, Dakar, Sénégal \\ ${ }^{3}$ Thoracic and Vascular Surgery Department of FANN University Teaching Hospital, Dakar, Sénégal \\ Email: *amadoukasse@hotmail.com
}

How to cite this paper: Kassé, A.N., Diao, S., Gaye, M., Sané, J.C., Hope, J.M.V., Hemmam, K., Thiam, B., Dieng, P.A. and Sy, M.H. (2018) Threatened Aortic Injury by Thoracic Pedicle Screw: A Case Report. Open Journal of Orthopedics, 8, 51-56. https://doi.org/10.4236/ojo.2018.82007

Received: December 26, 2017

Accepted: February 9, 2018

Published: February 12, 2018

Copyright $\odot 2018$ by authors and Scientific Research Publishing Inc. This work is licensed under the Creative Commons Attribution International License (CC BY 4.0).

http://creativecommons.org/licenses/by/4.0/

\begin{abstract}
Iatrogenic vascular injury during posterior spinal surgery is a rare but potentially serious complication with treatment challenges. We report the case of threatened aortic injury by pedicle screw impingement during posterior fixation of thoracic spine T7 - T8 fracture dislocation. The removal of the conflicting screws was done posteriorly after a visual control of the absence of adventitious break-in by a thoracotomy.
\end{abstract}

\section{Keywords}

Thoracic Spine, Pedicle Screw, Aorta, Thoracotomy

\section{Introduction}

Pedicle screws have been used successfully for posterior spinal fixation. Their biomechanical superiority and advantages in terms of fusion rates, coronal balance restoration and functional outcome are well established. Pedicle screw insertion requires thorough knowledge of the pedicle and vertebral anatomy [1]. Iatrogenic aortic injury by pedicle screw instrumentation is a rare complication during posterior reconstructive surgery of spinal deformity, spinal traumatic injuries and spinal degenerative disease [2]. Complications of posterior spinal instrumentation with pedicle screws, although rare, are known and are usually neurological [1]. Vascular complications, acute or secondary, have been reported in the literature mainly in the scoliotic kyphosis surgery [1] [3]-[11]. Regardless of approach, the anatomical proximity to the vertebral column places the descending aorta at increased risk of injury from procedural manipulation and 
screw migration during the posterior thoracic spinal surgery [1] [2] [3]. We report the case of iatrogenic threatened aortic injury by pedicle screw instrumentation during posterior reconstructive surgery of thoracic spine fracture dislocation.

\section{Case Report}

It was a 48-year-old female patient with no past medical and surgical history, admitted in the emergency department for polytrauma two hours after a domestic accident: collapse of a concrete floor slab on her during stormy weather in precarious housing estates.

The injuries found on admission were:

- A T7 - T8 fracture dislocation with burst fracture of T7 (Figure 1) and paraparesis of the right lower limb scaled ASIA D,

- A fracture of the body of the sternum,

- A fracture of the posterior arch of the fifth and sixth left ribs with mild left pleural effusion,

- A pilon fracture of the distal tibia associated with a fracture of the one fourth $(1 / 4)$ distal of the right fibula.

She underwent in emergency an open reduction and posterior fixation of T5 to T10 with freehand placement of pedicle screws on T5, T6, T8 and T9 under lateral fluoroscopic control. No intraoperative incident was noted. Control $\mathrm{X}$-rays and CT-scan showed a satisfactory reduction but with obviously too long screws (Figure 2). The MRI revealed the impingement between the proximal screws and the azygous vein and the esophagus while the left distal screws (T8 and T9) were in close contact with the descending aorta but could not confirm their intra or extra luminal status (Figure 3).
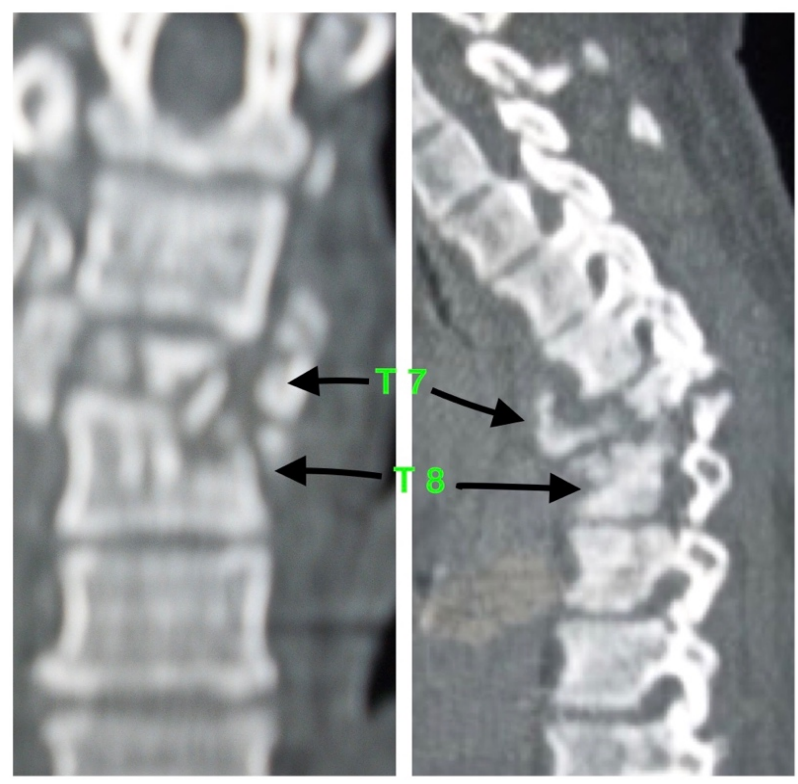

Figure 1. Fracture dislocation of T7 - T8 with burst fracture of T7 and T8. 

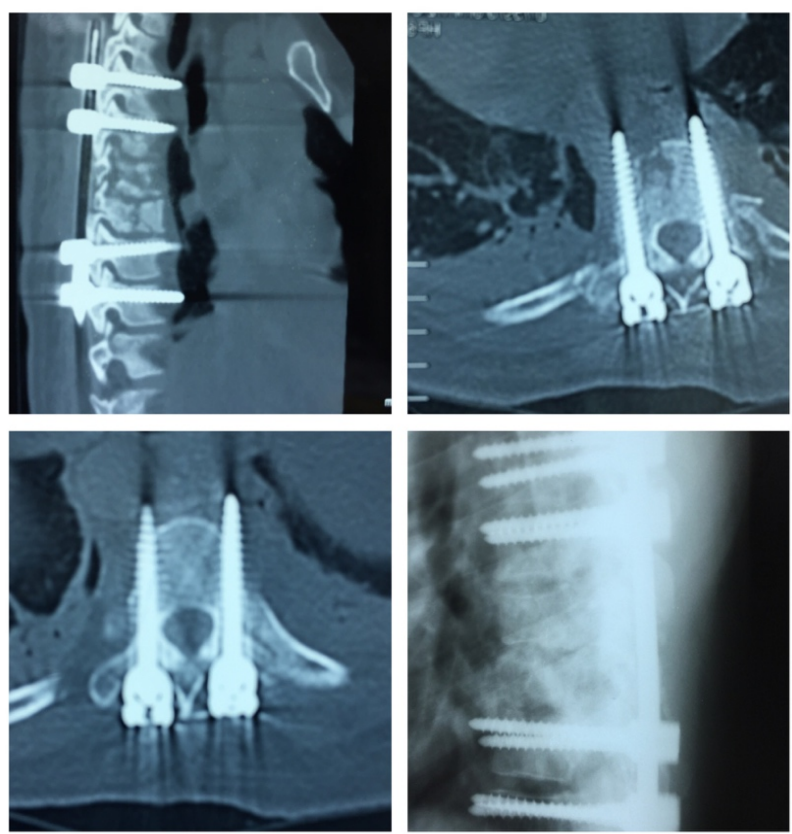

Figure 2. Control X-rays and CT-Scan showing too long screws potentially impinging the great vessels.
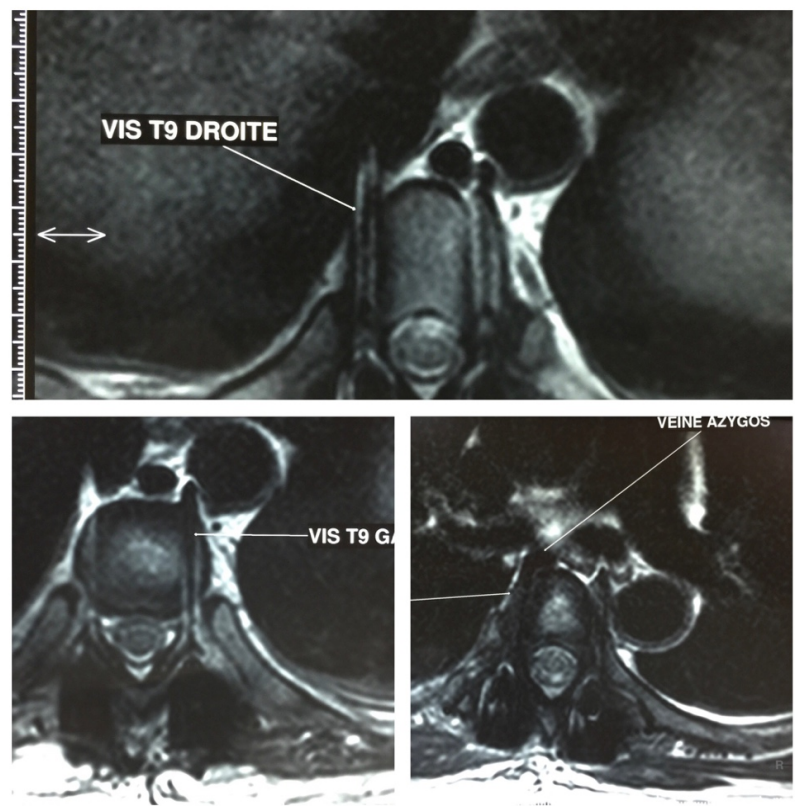

Figure 3. MRI showing conflicts between left T9 screw-Aorta and right T9 screw-Azygous vein.

In lateral position, an exploratory thoracotomy in the seventh left intercostal space at twenty-second day found that the descending aorta came into contact with the left pedicle screws at T8 and T9 without adventitial break-in (Figure 4). Removal of the four (4) left screws was performed posteriorly with endothoracic control. The aftermaths of surgery were therefore simple and straightforward with complete neurological recovery at the sixth month of follow-up. Bone 

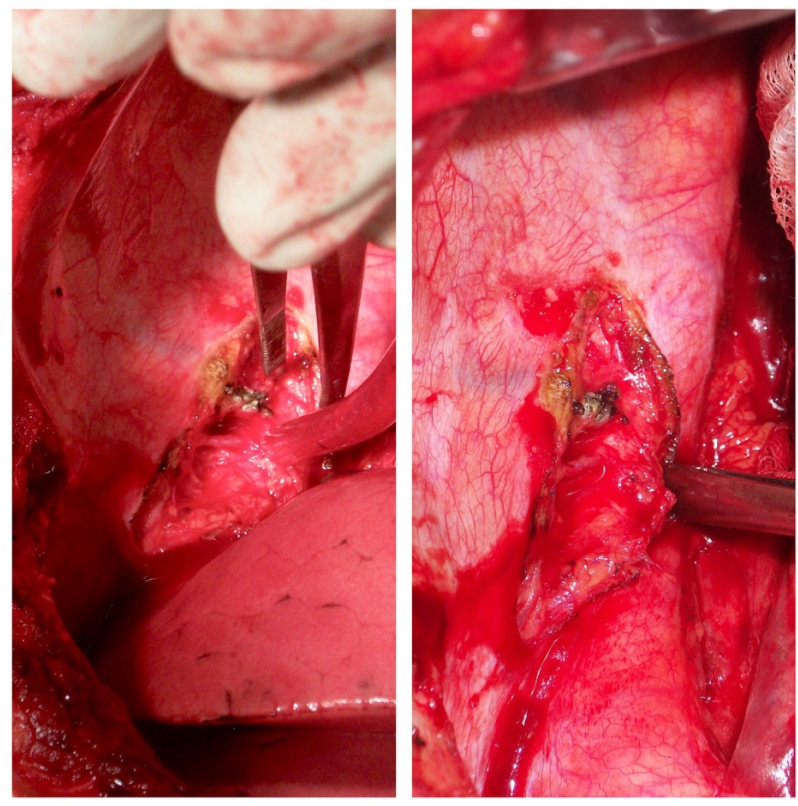

Figure 4. Intraoperative endothoracic view with aortic impingement without adventitia break-in.

healing was achieved and no vascular solutions were noted in the follow-up and at the reassessment time at the fifth year follow-up (Figure 5).

\section{Discussion}

Iatrogenic major vascular injury during posterior spinal surgery is a rare but potentially devastating complication [1]. Some rare cases of aortic injuries by pedicle screws in spine surgery were described in the literature [1] [3]-[13]. These injuries can present as an immediate hemorrhage in the operating room [12]. Their recognition is most often postoperative on the reading of the control imaging or the presenting clinical signs [12]. In our case, the diagnosis of aorta impingement was found on the control X-rays and confirmed by CT angiography and MRI. Both later exams usually help to diagnose the conflict and establish the therapeutic plan [3] [4]. It is however difficult to confirm the intra or extra luminal position of the conflicting screw as illustrated in our case. When spinal hardware abuts the aorta, we recommend removal of the hardware as pseudoaneurysm or even aortic perforation can present weeks to months later. The spectrum of injuries includes vessel perforation leading to hemorrhage, delayed pseudoaneurysm formation, and threatened perforation by screw impingement on arterial vessels [7] [10] [11] [12].

However, techniques differ from authors. The blind technique of removal of the screw is illogical and dangerous with risk of major hemorrhage. The removal of the misplaced screw under visual control through a thoracotomy seems more reasonable [4]. Depending on the extent of the defect, this could be performed with direct repair, patch angioplasty, or interposition grafting. However, open surgical repair can carry a high morbidity rate than screw removal after 


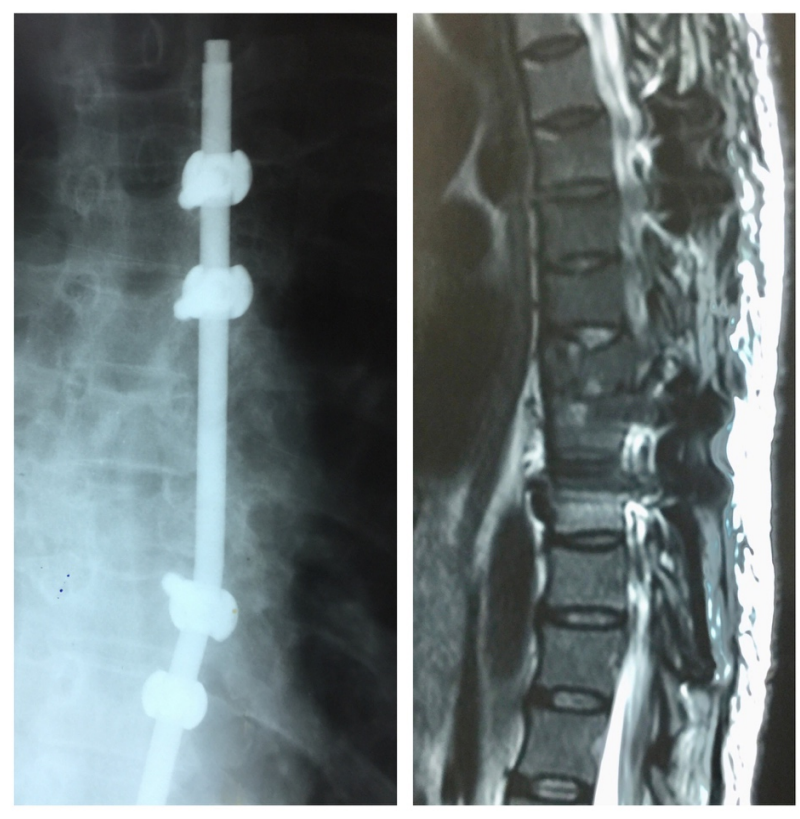

Figure 5. X-ray and MRI control at the reassessment showing bone healing without vascular injury.

placement of a protective aortic stent. The unavailability of this implant in our environment forced us to practice a conventional thoracotomy. However, the accuracy of pedicle screw placement has always been a major drawback, in association with possible injury of vital structures such as aorta, vena cavaor spinal cord; thus knowledge of perfect pedicle screwing is essential to prevent these complications. Although endovascular approaches have benefits in aortic aneurysm repair, the techniques of open thoracic aortic repair remain relevant; so various techniques described do not themselves guarantee total safety [2] [14]. The intraoperative fluoroscopic guidancewith navigation is a good and useful tool for checking the correct positioning of the screws [14].

\section{Conclusion}

Iatrogenic vascular injury during posterior spinal surgery is a rare but potentially serious complication. Their occurrence is always dramatic and their management is challenging. The prevention requires good operative planning with a perfect screwing technique under modern intraoperative fluoroscopic guidance.

\section{Informed Consent}

Informed consent was obtained from the patient to report this case.

\section{References}

[1] Hicks, J.M., Singla, A., Shen, F.H. and Arlet, V. (2010) Complications of Pedicle Screw Fixation in Scoliosis Surgery. A Systematic Review. Spine, 35, 465-470. https://doi.org/10.1097/BRS.0b013e3181d1021a

[2] Vaccaro, A.R., Rizzolo, S.J., Balderston, R.A., Allardyce, T.J., Garfin, S.R., Dolinskas, 
C. and An, H.S. (1995) Placement of Pedicle Screws in the Thoracic Spine. Part II: An Anatomical and Radiographic Assessment. The Journal of Bone and Joint Surgery, 77, 1200-1206. https://doi.org/10.2106/00004623-199508000-00009

[3] Nasser, R., Yadla, S., Maltenfort, M.G., Harrop, J.S., Anderson, G., Vaccaro, A.R., Sharan, A.D. and Ratliff, J.K. (2010) Complications in Spine Surgery. Journal of Neurosurgery. Spine, 13, 144-157. https://doi.org/10.3171/2010.3.SPINE09369

[4] Bastard, F., Loubière, H., Talha, A., Brux, J.L., Enon, B. and Fouquet, O. (2014) Sub-Intimal Erosion by Spinal Arthrodesis Screw in a 18 Years Old Female Patient. Chirurgie thoracique et cardio-vasculaire, 18, 49-51.

[5] Pesentia, S., Bartoli, M.A., Blondel, B., Peltier, E., Adetchessi, T. and Fuentes, S. (2014) Endovascular Aortic Injury Repair after Thoracic Pedicle Screw Placement. Orthopaedics \& Traumatology-Surgery \& Research, 100, 569-573.

https://doi.org/10.1016/j.otsr.2014.03.020

[6] Tong, X., Gu, P., Yu, D., Guo, F. and Lin, X. (2015) An Endovascular Treatment of a Thoracic Aortic Injury Caused by a Misplaced Pedicle Screw: Case Report and Review of the Literature. Journal of the Formosan Medical Association, 114, 464-468. https://doi.org/10.1016/j.jfma.2013.09.014

[7] Kakkos, S.K. and Shepard, A.D. (2008) Delayed Presentation of Aortic Injury by Pedicle Screws: Report of Two Cases and Review of the Literature. Journal of Vascular Surgery, 47, 1074-1082. https://doi.org/10.1016/j.jvs.2007.11.005

[8] Minor, M.E., Morrissey, N.J., Peress, R., et al. (2004) Endovascular Treatment of an Iatrogenic Thoracic Aortic Injury after Spinal Instrumentation: Case Report. Journal of Vascular Surgery, 39, 893-896. https://doi.org/10.1016/j.jvs.2003.10.056

[9] Hu, H.T., Shin, J.H., Hwang, J.Y., Cho, Y.J., Ko, G.Y. and Yoon, H.K. (2010) Thoracic Aortic Stent-Graft Placement for Safe Removal of a Malpositioned Pedicle Screw. Cardiovascular and Interventional Radiology, 33, 1040-1043. https://doi.org/10.1007/s00270-009-9782-5

[10] Tschoeke, S.K., Gahr, P., Krug, L., Kasper, A.S., Heyde, C.E. and Ertel, W. (2011) Late Diagnosis of Pedicle Screw Malplacement with Perforation of the Thoracic Aorta after Posterior Stabilization in a Patient with Multiple Myeloma: Case Report. Spine, 36, E886-890. https://doi.org/10.1097/BRS.0b013e318202e4d1

[11] Wegener, B., Birkenmaier, C., Fottner, A., Jansson, V. and Dürr, H.R. (2008) Delayed Perforation of the Aorta by a Thoracic Pedicle Screw. European Spine Journal, 17, S351-S354. https://doi.org/10.1007/s00586-008-0715-9

[12] Jendrisak, M.D. (1986) Spontaneous Abdominal Aortic Rupture from Erosion by a Lumbar Spine Fixation Device: A Case Report. Surgery, 99, 631-633.

[13] Kokotsakis, J., Misthos, P., Sakellaridis, T., Farsaris, D., Anagnostakou, V., Spiliotopoulos, K. and Lioulias, A. (2010) Emergent Endovascular Repair as Damage Control Step of Aortic Injury after Posterior Spinal Instrumentation. The Annals of Thoracic Surgery, 89, 1304.

https://doi.org/10.1016/j.athoracsur.2009.07.087

[14] Gelalis, I.D., Paschos, N.K., Pakos, E.E., Politis, A.N., Arnaoutoglou, C.M., Karageorgos, A.C., Ploumis, A. and Xenakis, T.A. (2012) Accuracy of Pedicle Screw Placement: A Systematic Review of Prospective in Vivo Studies Comparing Free Hand, Fluoroscopy Guidance and Navigation Techniques. European Spine Journal, 21, 247-255. https://doi.org/10.1007/s00586-011-2011-3 